\title{
The Cultural Exchange between Sino-Western: Silk Trade in Han Dynasty
}

\author{
Xiaoyan Wang \\ Center for Studies of Education and Psychology of Ethnic Minorities in Southwest China \\ Southwest University \\ 2 Tiansheng Road, Beibei District, Chongqing 400715, China \\ E-mail: tq06na0@163.com \\ Jinsuo Zhao \\ Research Center of the Economy of the upper Reaches of Yongtze River \\ Chongqing Technology and Business University \\ 19 Xuefu Street, Nan'an District, Chongqing 400067, China
}

Received: August 2, 2011

Accepted: October 26, $2011 \quad$ Published: January 1, 2012

doi:10.5539/ach.v4n1p13

URL: http://dx.doi.org/10.5539/ach.v4n1p13

This article was supported by the MOE Project of Key Research Institute of Humanities and Social Sciences of Chongqing, Project Number: 09SKB14.

\begin{abstract}
As we all know, the Silk Road, as a famous ancient transportation route, was a trade line cross-Eurasian continent in history. Its name was from the delivery of silk. However, no Chinese ancient documents mentioned the name of "Silk Road". German F. V. Richthofen (1933-1905) firstly used the term "Silk Road" in his book China, published in 1877. Afterwards, the name of "Silk Road" has been accepted universally and used by the world widely. The Silk Road was an ancient business channel, acrossing the middle of China and countries in Central Asia, gradually forming after Qian Zhang visited Western Regions twice, two thousand and one hundred years ago. The north-west land Silk Road started from Chinese ancient Capital Chang'an (now Xi'an), acrossing Central Asia, and reaching ancient Rome in Europe. It was a bridge for communication of politics, economy, and culture between ancient China and the Western. Before 11 Century, the Sino-Western silk trade mainly depended on the land transportation. During Han Dynasty, it was a competition between the Huns and the Hans for occupy the Silk road. The silk as a kind of material culture was a sort of intermediary for making people to know how to get along together.This article attempts to describe the Sino-Western silk trade conditions before and after the two missions of Qian Zhang to Western Regions (Xiyu), including archaeological evidences, kinds of silk and trade scale, transportation routes, trade participants, and so on.
\end{abstract}

Keywords: Han Dynasty, Silk, China, Rome, Trade

\section{China's Silk production and the Western demand for Chinese Silk}

China is the first country starting sericulture and silk weaving in the world. It was said that as early as the time of $\mathrm{Fu} \mathrm{Xi,} \mathrm{Chinese} \mathrm{knew} \mathrm{sericulture.} \mathrm{No} \mathrm{later} \mathrm{than} \mathrm{the} \mathrm{time} \mathrm{of} \mathrm{Emperor} \mathrm{Yellow,} \mathrm{people} \mathrm{began} \mathrm{to} \mathrm{make} \mathrm{closes} \mathrm{by} \mathrm{silk.}$ Archaeologists unearthed more than 6900 years old textile tools and silkworm pictures of the Neolithic Age in Yuyao, Zhejiang province, and more than 4700 years old plain silk sheets of the Neolithic Age in Qianshanyang, Wuxing County, Zhejiang province, which proved that Chinese ancestors had woven silk at the Neolithic Age. At the Warring States Period (475 BC-221 BC), the silk products in China were various, covering Juan, Wan, Luo, Gao, Sha, Tao, Qi, Jin, and other more than ten types, even including ambroidered silk with delicate patterns. For example, the woven Jin unearthed from a tomb of Country Chu at the Warring States Period and the Jin from a 
tomb of the same Time was woven by two kinds of silk with three colors. The patterns were smooth, various, and colorful. Not only the silk-weaving technology tended to be mature, but also was the scale of production beyong the former age. For instance, the exchange of silk between princes at the Spring and Autumn Period (770 BC-475 BC) as a predent was about $30 \mathrm{Pi}$ (an ancient unit of measure, about 13.33 meters) once, but at the Warring States Period, the amount was beyond one thousand Pi. At that time, both the government and the private workshops and families could produce silk. The government appointed special agent to run the production of silk, which was mainly for the upper class, instead of exchange. The private workshops produced silk for circulation in market, not only in China but also in the West.

Chinese silk exported to the West. It was a solid fact with archaeological proofs. Amounts of Chinese silk has been found in clusters of tombs in Cartoon River (the area of Katanjin), Bolaili River (the area of Bolaili), Wuer Suer River (the area of Xibin, Basha Daer, etc.), Wulagan River (the area of Baze Leike) of Altai Region of Gorno in the former Soviet Union. These silk was produced in the $6^{\text {th }}$ century B.C. to the $5^{\text {th }}$ century B.C. In Village Stuttgart, Hawk Davidoff, Germany, archaeologist unearthed Chinese silk woven in $5^{\text {th }}$ century B.C. From the clay spots with red flowers patterns, which were manufactured in Athens in $5^{\text {th }}$ century B.C., archaecologists found extremely thin cloth. Similar fabric was also found from clay spots Aoxisuo and Pengbei produced in the mid- $4^{\text {th }}$ century B.C. In a Greek ivory painting "Polis Judge" from the $3^{\text {rd }}$ century unearthed from Crimean Peninsula, the godness wore transparent tulle, showing her breast and navel. These items prove that at the era of Greece and Rome Chines silk has won the love of ancient Greek and Roman, especially the nobility, who had pursued the Chinese silk as the gorgeous, elegant, and fashinable apparel.

Because of the export of Chinese silk to the West, the Greek has named China as "Seres" around the $5^{\text {th }}$ century B.C. "Seres" is Greek, meaning the place producing silk or people selling silk. These facts confirm that Chinese silk has exported to the West far before the mission of Qian Zhang to Western Regions.

However, for a very long period, the West only imported silk but did not know how to weave silk. Untill the $1^{\text {st }}$ century AD the naturalist Gais Pliny did not know where silk came from. He believed Chinese silk grew in trees in his "Natural History". Because silk was from faraway China, long distance resulted in expensive silk. The price even reached $600 \mathrm{~g}$ gold per pound silk. The Rome nobility was crazy for Chinese silk, which caused a huge loss of golden coins. Therefore, the Rome senate forbad people to wear silk clothes for many times. However, it did not stop the sale of Chinese silk in Rome at all.

Chinese silk is world-famous with its soft, gentle, colorful, and dazzling nature. People from all countries in the world love to wear silk. The Rome named Chinese silk as "Dayeboer", meaning "vivid" and "realistic" in Greek. Lucette Boulnois said in his The Silk Road: "After the Rome knew silk, they not only spoke highly of it, but also sought for it." Gais Pliny in his Natural History recorded: Chinese silk "woven beautiful cloth and shipped into Rome. The rich and noble women wore silk clothes, shining all the time." It was said that Julius Caesar, dressed in eye-catching Chinese silk gown, had watched operas in big theater and won the audiences' sensation. Then, the Rome nobility competed with each other with luxury silk clothes and decorations. After Qian Zhang's two missions to Western Regions, the way from China to Eurasian continent was established and amounts of Chinese silk was exported to European and mid-Asian countries. Untill the $4^{\text {th }}$ century A.D., the Rome, whoever rich or poor, could able to wear silk clothe, as the trade relation between Rome and China was set up after Qian Zhang mission to Western Regions.

\section{Qian Zhang's Mission to Western Regions (Xiyu)}

Before I reach the Qina Zhang's Mission, let me say a little bit of silk productions that made in the Central Plains. In Han Dynasty (202 BC-AD184), techniques of silk-made, texitile, dyeing, and emroidery have improved significantly. Various silk appeared, including Jin, Qi, Luo, Sha, Gao, Su, Lian, Jian, Juan, Ling, Chou, Wan, Man, Qing, Fu, etc. Patterns were richer, such as clouds pattern, geometric pattern, bird and animal pattern, auspicious words pattern, and hunting patterns. The most famous silk was from Shandong province. Clothes of royal families were made of contributed silk from Xiangyi. The Han royal government gave more than ten thousand Pi silk as presents to chiefs of the Hun and other western tribes.

The Emperor Wu of Han, Che Liu was a kind of crave for greatness and success. As the Hun threaten the Empire for many years, he decided to defeat it. The aim of Qian Zhang's Mission to Western Regions for an allaince with the Darouzhi, nomadic people who migrated from north areas of the Central Plains to west for escape from the Hun's hitting decades ago, to strike the Hun together. With the national mission, Qian Zhang started with over 100 people for Western Regions in 139 BC. when Qian Zhang returned from Western Regions after suffering hardship travelling and mang setbacks of thirteen years, the whole country was excited, although he did not reach the Darouzhi, and lose almost all people on the his mission trip but two. He described the geography, 
products, and ethnic customs and everything what he caught in his sight, which greatly widen the eyesight of Chinese, especially the fine horses, grapes, and other unknown fruits. Then, the Emperor Wu of Han realized the important political meanings and the irresistible economic benefits from controlling the paths via Western Regions by military power. The royal government sent Qian Zhang as the specia envoy to Western Regions again (119 BC-115 BC). Just as what Wenlan Fan said: "The return of Qian Zhang brought news of Western Regions and promoted the culture communicaton of the East-West. His return was a memorable event in human history." People even compared impacts of the return of Qian Zhang on the Central Plains with the inspirations of Columbus Discovery to the world, and they spoke highly of the former over the later. In a word, afterwards, the way from Central Plains to Western Regions kept smooth, guaranteeing the safety of diplomats and merchants. The silk trade becamm,e flourished gradually.

The two missions of Qian Zhang to Western Regions formed the basic route of Silk Road, namely the Silk Road in a narrow meaning. According to the political and geographical distribution at that time, people divided the entire Silk Road into three sections from the east to the west: the eastern section, the middle section, and the western section. The eastern section started from the Capital Chang'an (Xi'an, Shaanxi province now) in the Western Han Dynasty or the Capital Luoyang (Henan province now) in the Eastern Han Dynasty, across the Hexi Corridor, Yumen Pass or Yang Pass, entering the middle section of Silk Road, namely the section in Western Regions. In Han Dynasty, the section of Silk Road in Western Regions included the south path and the north path. The north path ran through the south side of Tianshan and the north edge of Taklimakan Desert. The south path was between the north side of Kunlun Mountains and the south edge of Taklimakan Desert, across Congling (Pamir now), entering the western section of Silk Road, passing Dayuan (Ferghana now), Bactria (in Afghanistan today), Sogdiana (in Uzbekistan today), Anxi (Iran now), and reaching Liqian of Daqin (the ancient Roman empire).

Encouraging by Qian Zhang's missions to Western Regions, a group of ministers and merchants requested to visit Western Regions. According to the record in the book History of Han Dynasty, envoys and merchants were so many that they could see eath other on the road. The large group of envoys included several hundreds of people, and the small group included more than one hundred people. In one year, five to six, or even ten groups of envoys started or accomplished their missions. They followed different ways in the mission. They spent eight or nine, at least several years in their travelling. These envoys, sent by the royal government, were not only for the sake of politics, but also for the sake of trade. They usually carried a number of commodities, mainly amounts of delicate silk, as the medium of exchange. Qian Zhang was not an exception. In his second mission, he brought "ten thousands of cattles and sheep, and thousands of golden coins and silk". His vice envoy and business team took amounts of Chinese silk and other local products to the west places, such as Dayuan (Ferghana now), Kangju (in Uzbeks today), Darouzhi (now the upper reaches of the Amu Darya, the north of Afghanistan), Bactria (in Afghanistan today), Anxi (Iran now), Sindhu (India), Khotan (now Hotan in Xinjiang), and Wuni (now Ruoqiang in Xinjiang). Private merchants also took a part in trade with the west.

\section{The Development of Sino-Western Silk Trade}

Qian Zhang and his vice envoy did not establish the silk trade with Rome directly. At the right time after Qian Zhang's mission to Western Regions, the Rome Empire grew strongly and powerfully. They had an increasing need for Chinese silk. How did Chinese silk reach Rome market? Pliny pointed out in his book Natural History that Chinese silk was transported from land or shipped to India firstly. Then, the Indian merchants took them to the west.

\subsection{Route}

Before Qian Zhang's mission to Western Regions, a minister of the ancient India Dynastyof Peacock wrote a book named Political Comments, which described the fact in $4^{\text {th }}$ century B.C. that Chinese silk was exported to India and then shipped to Greece and Rome by Indian merchants. Chinese silk to India passed the north-west land Silk Road, namely the southern section of Silk Road in Western Regions, which was divided into two paths after passing Pishan and Shache. Then they were transported toward the west to Darouzhi and Bactria, then toward the south-west to Xuandu (Keli'er in Pakistan now) and Dardisthan (Kabul in Afghanistan now), toward the south to estuary of India river (Karachi in Pakistan now), and finally to Persia and Rome by ship. However, this route was long and tough. The Sino-India trade on this route was not frequent. "Although cities on the route favored the market, the merchant team spent several years on the way." Untill around A.D. $3^{\text {rd }}-4^{\text {th }}$ century, Indian merchant teams chosen another tough but shorter route, which acrosses the valley of Indian River and Karakoram mountains, leading to Kashgar, Yarkand, and Wada. An Indian scholar Bagchi pointed out that: "The trade with China appeared as early as the time of Qian Zhang. Qian Zhang mentioned the trade by the Bruma 
Road and noticed the commodities from the southwest of China, shipped by Indian merchants." The fact was that Qian Zhang saw two things from China, the bamboo stick made in Xichang (Sichuan province now)and the flax cloth made in Sichuan, and local people said that these items were shipped by Indian merchants.

It was said that these goods were shipped via the southwest Yongchang route to India. The Whole Yongchang Route included two sections: the first was the Shaanxi-Sichuan section from Chang'an to Chengdu, and the second was the Chengdu-India section from Chengdu to India. The first section started from Chang'an, acrossing Qinling, old road of Chencang, Baoxie road, Jinniu road, and Jiange to Chengdu. The second section started from Chengdu, acrossing Maoniu road, Qiongdu (Xichang, Sichuan province now), Jinsha River, Yongchang County (the northeast of Baoshan in Yunan province today), Nu River, Yuecheng (Luxi of Yunan province now), Biao State (in Myanmar now), and to Dhaka in India. The stick and the cloth could be transported to India via the path. I don't think that Chinese silk had reached India via this way. And the Yongchang route was not a "silk road". At that time, most of silk productions were made in Hebei and Shandong province, then converged in the Capital Chang'an. The stick and the cloth what Qian Zhang saw in Bactria were made in Sichuang where did not need via the first section of Yongchang route. Silk were in Chang'an, it is impossible to be transported via the first section of Yongchang route. In Eastern Han Dynasty, untill Yongping $12^{\text {th }}$ year (AD 69) the Emperor set up Yongchang County, the Shaanxi-Sichuan section could be connect with the Chengdu-India section. But, just as we know, the first section of Yongchang route is the most difficult road in the world. A great poet of Tang Dynasty, Bai Li (AD 701-726), described the road in his poem: "What heights! It is easier to climb Heaven than take the Sichuang Road" So, in the era of Qian Zhang, Chinese silk could never be transported to India from southwest of China, and then to Rome from India.

We say that before and long after Qian Zhang's mission to Western Regions, Chinese silk was not transported via land roads to India. As some evidences we found from the documents of the Han history books that the Han royal envoys had taken gold and silk to countries near the south sea by the coast. At that time, harbors in the south of India were places for gathering and distributing silk and other commodities from China. After arriving at these harbors, silk would be shipped to Rome by Indian merchants through the Red Sea. Therefore, sea routes were the main ways for Chinese silk passing through India, then to Rome.

\subsection{Middleman}

India was one of the transit countries in sea silk trade. Then who was the land middle man in the trade? It was sure that the Huns dominated the north regions of Tianshan Mountains during the period of Western Dynasty, there was no way for traders passing Yiwu (Hami, Xinjiang Uygur autonomous region now). The south route of north-west land Silk Road was the only way for traders from Western Han Dynasty to Western Regions. Kroraina (Loulan) became the main transfer station for silk trade. Chinese silk was transported from Kroraina to Persia, then to Rome. When the vice envoy of Qian Zhang brought envoys of Dayuan, Kangju, Darouzhi, Bactria, Anxi, Sindhu, Khotan, and Wuni back to Chang'an, these regions began to directly exchange products with Han Dynasty. Afterwards, they sold Chinese silk to Rome. Most middle businessmen in silk trade was from Anxi. The "History of Western Regions" in "History of Post-Han Dynasty" recorded: "The King often hoped to send an envoy to Han Dynasty, but stoped by Anxi traders who wanted to monopolize Chinese silk." Ying Gan, the envoy of Eastern Han Dynasty who shouldered on the mission to visit the Rome in AD 97, when he arrived the coast of the Caspian sea, he heared : "The sea was immense. With lucky, people could pass it in three months. If met strong wind, it could spent two year. So people took foods for three years. Sometimes people just died of a sort of homesick on the ocean due to long time sea trip." Some researchers argued that what the local people told to Ying Gan's diplomatic corps so difficult to cross the sea was in order to control the silk middle trade with Rome. Ying Gan considered the time and the risk, and finally gave up the plan of visiting to Rome. He returned Luoyang. As a result, it delayed the set-up of silk trade connection between China and Rome for seventy years in totality.

\subsection{Profits}

After long-distance transportation and passing several traders, Chinese silk was as expensive as gold. It was said that one Pi of Chinese silk worthed 12 liang (ancient Chinese monetary unit, 16 liang amount half a kilo)gold. According to the estimation of Pliny in his Natural History, Rome lost at least 100 million golden coins to India, China, and Arabian Peninsula annully due to trade. According to Rome history documents, the import of silk valued 100 million Rome golden coins. In Han Dynasty, the Emperor Wu encouraged the trade and made policies, importing at high prices and exporting at low prices, using high profits to stimulate traders of Western Regions, Central Asia, and West Asia to participate into Sino-Western trade. The gold of Rome did not come to China completely. The trader from Anxi and Rome earned lots. In Rome, local traders earned ten times of profits 
by trading with Anxi and with India over the ocean.

Rich profits, like a magnet, acctracted merchants from Central Asia and Western Asia. They were in the middle of envoys came to the Central Plains. As the vice envoy of Qian Zhang returned from Western Regions, many merchants from different regions followed, in the name of contribution, engaging in silk trade. "The merchants traded silk in the name of contribution." After Chao Ban in Eastern Han Dynasty visited Western Regions, merchants from more than fifty countries joined the silk trade. They came and went, day and night. According to the Series of Western Region's Exploration of Aurel Stein, archaeologists found bamboo slips in foreign languages (Sughda, Kharosthi, Sanskrit), decorative fabrics, and slippers in western carpet patterns from archaeological sites in Xinjiang and Gansu. Obviously, along the way from Central Plains to Western Regions, there were many things of Central Asian merchants traveler left behind.

\subsection{The exchange of fabrics and techniques}

In addition to earning gold, the merchants in Han Dynasty exchanged all kinds of wool products with silk. In a letter to Chao Ban from his brother Gu Ban, "We planed to use three hundred Pi white silk to trade with Western Regions." An ancient poem named "Travel in Longxi" said: "Invitated guests into the north room, and asked them sat on a carpet". Longxi located in Northwest of Central Plains, the poem told that people used carpets which probably were exchanged from Western Regions. Aurel Stein exmined the fragments of delicate carpets unearthed from Han tomb in Tarim Basin and concluded that the style indicated Rome character undoubtedly. Whether they were produced locally or imported from Central Asia, it proved the power of culture. Thus, it proved that not only wool products were from ancient Greece and Rome, but also people in Tarim Basin absorbed the weaving techniques and patterns in their production of wool products.

\section{Conclusion}

Firstly, about the time of the silk trade existence, as the consensus of scholars, the Sino-Western silk trade existed before the Qian Zhang's mission to Western Regions, after the two his missions, the Silk Road was more smooth and prosperous. From the Han Dynasty to Tang Dynasty, the Sino-Western silk trade mainly depended on the land transportation before 11 Century. Secondly, At ancient time, Western Regions, as the necessary channel for land transportation of silk trade, was always grabbed by strong nomadic tribes in the north or Dynasties in Central Plains. During Han Dynasty, it was a competition between the Hun and the Han for occupy the Silk road. Thirdly, The Sino-Western silk trade was not run by one-stop type. It depended on many middlemen and its relay-stations. The Sino-Western silk trade in the Silk Road was not a one-way output of silk from China, but a mutual exchange of diverse commodities. Finally, the connection betweem Sino-Western of silk trade made a relationship betweem them, that exchange material cultures, silk, wool woven, and even plants. With the productions's advent, technics had been transmitted in the new areas. The silke had played an important role in the development of human society. The long term of silk trade relationship had pushed some societies changed, Romans consumed silk but gold drained, Parthian got money, Chinese silk got promotion, etc. It is easier to transmit technics than to make relation between people, or two ethnic groups, or two countries. Human relations had showed a significant meaning in human history already. Through out the silk trade of Han dynasty, human relations in society made the long distance silk trade to be possible. Different people have being created different cultures. But interculture exchange needs social relations. The Sociality is always the nature of human being, the culture is a sort of intermediary for making people to know how to get along together.

\section{References}

Ban, G.. History of Western Regions. The History of Han Dynasty. Vol.96, 32-92.

Fan, W. L. (1949). The Concise Edition of General History of China. Beijing: People's Publishing House.

Fan, Y.. History of Western Regions. The History of Later Han Dynasty. Vol.88, 398-445.

Klimkeit, H. J. (1994). Culture of Ancient Silk Road. Translated by Zhao, Chongmin. Urumchi: Xinjiang Art and Photography Press.

Li, M. W. (1997). History of Silk-Road Trade. Lanzhou: Gansu People's Publishing House.

Stein, A. (2010). Series of Western Region's Exploration. Translated by Xiang, Da. Urumchi: Xinjiang People's Publishing House. 